\title{
MÚSICAS DE TRABALHO NO MUNDO ATLÂNTICO
}

Paulo Cruz Terra

\author{
Mestrando em História na Universidade Federal Fluminense
}

Resumo: O objetivo deste artigo é buscar quais os papéis da música no processo de trabalho dos carregadores negros, na cidade do Rio de Janeiro, no século XIX. Verifico também, qual o papel da música na relação entre a experiência dos negros, na África, e nas Américas. Mostro que é possível perceber semelhanças, entre os cantos entoados pelos carregadores do Rio de Janeiro e a música dos africanos, no Mundo Atlântico. Semelhanças essas que estavam presentes, na forma como eles cantavam essas canções, a "chamada e resposta", além da função de imprimir ritmo e dar uniformidade ao trabalho. O que havia de específico eram as letras cantadas, refletindo características próprias da vida cotidiana.

PALAVRAS CHAVE: música - trabalho - negros - Atlântico

\begin{abstract}
The purpose of this article is analyze what are the roles of music in the working process of the black porters in Rio de Janeiro in the XIXth century. I verify also what is the role of music in the relationship of the experience of the black people in Africa and in the Americas. I suggest that is possible to recognize similarities between the songs of black porters in Rio de Janeiro and the work songs of Africans in the Atlantic World. Similarities like the form they sing the songs, the "call and response", and the function of coordination the rhythm and make uniform the work. The specificity was the lyrics of the songs, where they put the characteristics of their own daily life.
\end{abstract}

KEY WORDS: songs - work - black people - Atlantic

\begin{abstract}
Num dos primeiros dias de minha estada [no Rio de Janeiro] movido pela curiosidade fui forçado a deixar minhas atividades. É que ouvira certos sons estranhos, repetidos de um a outro extremo da rua: tratava-se simplesmente de uma mudança. Cada negro levava um móvel, pequeno ou grande, conforme sua escolha ou conveniência; todos corriam juntos repetindo uma ou duas sílabas acompanhadas de sons guturais (...) na esteira da longa fila (formada de uns cinqüenta negros) vinha, gravemente conduzido por seis homens, um piano de cauda; à frente, um deles fazendo de chefe de orquestra, empunhava uma cabaça cheia de pedrinhas; com esse instrumento, o negro marcava, alegremente, o compasso. O piano era levado nas cabeças, sem qualquer auxílio das mãos, hábito generalizado entre os pretos (BIARD, 1862, p.80).
\end{abstract}

A passagem acima foi escrita pelo francês F. Biard, que esteve no Brasil em 1858. Assim como ele, outros viajantes registraram a presença da música, em quase todos os tipos 
de trabalho de carregamento, no Rio de Janeiro no século XIX. Daniel Kidder, que andou no país, entre 1837 e 1838, afirmou ter ouvido carregadores de café, das ruas do Rio andarem na marcação de "alguma canção selvagem de suas pátrias distantes" (KIDDER, 1940, p.47). Ewbank foi mais específico, e expôs que o canto que ouviu era de Angola (EWBANK, 1976, p.78). O olhar desses viajantes, no entanto, mostrou-se, geralmente opaco, para perceber quais os significados que as músicas poderiam ter na experiência dos trabalhadores, bem como o papel desses cantos, na relação entre a África e a vida dos cativos do lado de cá do Atlântico. Robert W. Slenes afirmou que "os contemporâneos do tráfico de escravos escreveram pouquíssimos relatos que falam diretamente a respeito das culturas de origem dos cativos, ou da interação entre essas culturas, no Novo Mundo" (SLENES, 1991-1992, pp.48-49). A porção da África, no Brasil, permanecia coberta, assim como vários aspectos da experiência dos escravos.

O objetivo deste artigo é, justamente, buscar quais os papéis da música, no processo de trabalho dos carregadores e também na relação entre a experiência dos negros, na África e nas Américas. Pretendo, ainda, analisar o que há de comum e também de diferente, entre os cantos entoados pelos carregadores, no Rio de Janeiro do século XIX, e aqueles dos trabalhadores negros do Mundo Atlântico. Ao focar-me na música, entoada durante o processo de trabalho, sigo a proposição de João José Reis, de que, a força da cultura escrava deve ser entendida em conexão com a experiência do trabalho dos escravos. Não se trata, no entanto, "de deduzir cultura de processos e relações de trabalho, uma operação funcionalista e conservadora, mas de considerar que os escravos não suspendiam a produção de significados culturais durante a produção de mercadorias e serviços" (REIS, 1993, p.11).

Os estudos historiográficos, que trataram sobre os carregadores negros no Rio de Janeiro, assim como suas fontes principais, os viajantes estrangeiros, não abordaram, detidamente, a questão da música e das relações entre África e Américas. ${ }^{1}$ Em artigo de

\footnotetext{
${ }^{1}$ Trabalhos que tratam dos carregadores no Rio no século XIX: Marilene Rosa Nogueira da Silva. Negro na rua: a nova face da escravidão. São Paulo: Hucitec; Brasília: CNPq, 1998; Luiz Carlos Soares. "Os escravos de ganho no Rio de Janeiro do século XIX”. Revista Brasileira de História, 16 (Mar/ ago.1998). Marco Zero/ ANPUH; Mary C. Karasch. A vida dos escravos no Rio de Janeiro (1808-1850). São Paulo: Cia das Letras, 2000; Maria Cecília Velasco e Cruz. "Tradições negras na formação de um sindicato: Sociedade de Resistência dos trabalhadores em trapiche e café, Rio de Janeiro, 1905-1930.” Afro-Ásia 24 (2000). CEAO/ FFCH/ UFBa; Leila Mezan Algranti. O feitor ausente - estudo sobre a escravidão urbana no Rio de Janeiro. Petrópolis: Vozes, 1988. Mary Karasch é a única exceção entre os autores citados acima no que diz respeito a
} 
1995, a historiadora Silvia Hunold Lara afirmou que as novas interpretações sobre a experiência da escravidão no Brasil têm, cada vez mais, revelado um grande desconhecimento, da maior parte dos historiadores, em relação à cultura africana. Segundo ela, se hoje temos novas análises sobre a relação senhor-escravo, é preciso redimensionar os estudos sobre o "lugar" das culturas africanas (LARA, 1995, p.52). Alberto da Costa e Silva, por sua vez, expôs que, finalmente, essa situação está mudando e que está se começando a procurar o lado africano da história da escravidão no Brasil (COSTA E SILVA, 2004, p.23).

O debate sobre o papel das culturas africanas, nas experiências dos cativos nas Américas, divide-se, em linhas gerais, entre aqueles autores que enfatizam a ruptura entre África e as Américas e aqueles que frisam a continuidade. Segundo Mathias Röhrig Assunção, dois antropólogos americanos trocaram argumentos sobre a questão na década de 1940. Para Franklin Frazier, "os escravos teriam sido arrancados de suas culturas ao ponto de o passado africano ser reduzido a 'memórias esquecidas"' (ASSUNÇÃO, 2003, p.160). A cultura escrava seria, então, resultado, principalmente, da opressão e adaptação dos escravos a ela. Melville Herskovits, por sua vez, insistiu nas características culturais comuns, partilhadas pelos escravos provenientes de diversas regiões da África. E, como essas semelhanças permitiram a permanência de elementos e instituições africanas nas Américas, Assunção considerou que um modelo reconciliador, de ambas as posições, foi proposto por Sidney Mintz e Richard Price. Eles não negariam as contribuições africanas, mas afirmariam que, nem o contexto social nem as tradições culturais, quando vistas sozinhas, podem explicar uma forma institucional afro-americana, e a formação das instituições devem ser analisados em todo seu desenvolvimento histórico. Eles concluíram que, as continuidades formais da África, na cultura afro-americana, foram mais exceção do

\footnotetext{
busca de relações entre o trabalho desenvolvido pelos carregadores no Rio de Janeiro e pelos carregadores da África. Karasch afirma, por exemplo, que "os senhores aproveitaram a tradição do ofício de carregador na África e os extraordinários poderes de resistência que certos africanos desenvolviam”. Ela baseia essa informação no relato de Joachim John Monteiro, que teria viajado, em Angola, em rede com pouca bagagem, por uma distância de cerca de $200 \mathrm{~km}$, em apenas quatro dias com oito carregadores que, sem mostrar cansaço, dançaram várias noites. O relato de Monteiro pode nos informar sobre os carregadores em uma região específica da África, mas não a forma como os senhores aproveitaram essa tradição aqui no Brasil, ou como os próprios carregadores podem ter feito uso dos conhecimentos que possuíam. Mary C. Karasch, op. cit., p.549.
} 
que regra e que, as categorias mais precisas, para expressar a realidade, deveriam ser "criação" ou "remodelação", ao invés de "empréstimo".

As expressões culturais dos cativos estão sempre no centro desse debate. Sterling Stuckey, por exemplo, analisou o papel da cerimônia ring shout na comunidade escrava dos EUA. Foi através dessa cerimônia que os cativos africanos reconheceram valores comuns, entre eles, e foi justamente a memória da África que permitiu a união. Stuckey buscou reconhecer os elementos africanos que persistiram nas experiências dos escravos norteamericanos, aproximando-se, assim, da posição de Herskovits. Aspectos presentes num ritual fúnebre, por exemplo, foram vistos, pelo autor, como marcando as comunidades escravas da Virginia como sendo africanas (STUCKEY, 1987, p.66).

Outros autores propõem que a interação entre a África e as Américas deve ser analisada dentro do contexto do Mundo Atlântico. Segundo Philip D. Morgan, na era moderna começou a emergir um mundo Atlântico cada vez mais integrado e coeso. Ao longo do tempo, uma variedade de redes, laços e conexões ligaram os territórios em torno do Atlântico, e se formou um sistema único, propriamente o sistema Atlântico. Para Morgan, a escravidão foi a face central desse sistema emergente, já que definiu a estrutura econômica, social, política, ideológica e cultural de várias sociedades Atlânticas (MORGAN, 1997, p.122).

Paul Gilroy, por sua vez, sugere que os historiadores culturais deveriam assumir o Atlântico "como uma unidade de análise única e complexa em suas discussões do mundo moderno e utilizá-la para produzir uma perspectiva explicitamente transnacional e intercultural" (GILROY, 2001, p.57). O Atlântico assume, justamente, um papel preponderante, na proposição do autor, de que as culturas dos cidadãos negros do Reino Unido foram produzidas em um padrão sincrético, no qual as formas e os estilos dos Estados Unidos, Caribe a África foram reinscritos e reelaborados, no contexto do conjunto de conflitos regionais e classistas do Reino Unido moderno.

\footnotetext{
${ }^{2}$ Nem todos consideram Sidney e Mintz como uma posição conciliadora. Segundo Paul Lovejoy e José Curto, autores como Sidney Mintz e Richard Price enfatizaram a rápida adaptação dos africanos escravizados as novas culturas nas Américas, enquanto Gwendoyn Hall e Douglass Chambers propuseram a sobrevivência e continuidade de características culturais africanas. Cf. Jose C. Curto; Paul E. Lovejoy. "Introduction" in: Enslavng connections: changing cultures of Africa and Brazil during he era of slavery. New York: Humanity Books, 2004. p. 14.
} 
Stuart Hall concordou com Gilroy de que o Atlântico negro é uma categoria bem mais útil para o estudo das diásporas que o referencial nacional (HALL, 2003, p.36). Hall analisou a música e a subcultura danceball na Grã-Bretanha e afirma que, apesar desse movimento se inspirar na música e na subcultura da Jamaica e adotarem muito de seu estilo e atitude, não é apenas um reflexo pálido de uma origem "verdadeiramente" caribenha. As configurações sincretizadas da identidade caribenha e de suas diásporas não podem ser concebidas, portanto, em termos de origem e cópia.

Apesar de identificar que a África vive nessa diáspora caribenha em alguns traços, como na retenção das palavras e nos padrões rítmicos da música, ele acredita que não se está ligado ao passado e à herança africana, por uma cadeia inquebrável, discordando, nesse ponto, de autores como Stuckey. A África que vive na diáspora "não é nem a África daqueles territórios agora ignorados pelo cartógrafo pós-colonial, de onde os escravos eram sequiestrados e transportados, nem a África de hoje, que é, pelo menos, quatro ou cinco 'continentes' diferentes, embrulhados num só, suas formas de subsistência destruídas, seus povos estruturalmente ajustados a uma pobreza devastadora" (HALL, 2003, p.40). A África que vai bem, nesta parte do mundo, portanto, não é aquela que é retomada, e sim criada. Dessa forma, Hall analisou a cultura, não apenas como uma viagem de redescoberta, e sim como uma produção.

As discussões sobre a música de trabalho dos negros também giram em torno da questão da continuidade ou ruptura de padrões culturais entre a África e as Américas. Entre as obras que consultei, o único autor que não tratou dessa questão foi Alain Locke. Uma das razões deve estar em que na época da produção do livro (a primeira edição data de 1936), essa questão não estivesse posta. Este autor afirmou que as músicas de trabalho eram compostas de várias pequenas linhas, repetidas com pausas, intervindo na batida de um martelo ou de uma picareta e era geralmente cantada por um grupo. E, apesar das canções sulinas, as mais antigas, fossem músicas de grupo e composições coletivas, em que uma pessoa liderava o canto, sendo o corpo da canção moldado em coros improvisados (LOCKE, 1988, p.30).

Miles Mark Fisher, por sua vez, iniciou seu livro sobre as canções dos escravos negros nos Estados Unidos, datado de 1953, mostrando a forma e a função da música para as populações que viviam na África. Segundo ele, "quando os negros africanos foram 
trazidos para a América eles carregaram consigo a sua música rítmica, corporal, voz e instrumentos. Eles possuíam músicas fixas, para todas as situações da vida e tinham habilidade para criar outras improvisadas" (FISHER, 1990, p.10). As canções dos escravos foram vistas assim como possuindo os mesmos significados das músicas para os africanos, sendo eles: valorizar acontecimentos contemporâneos, preservar as histórias do passado, promover a religião e comentar eventos da vida cotidiana. A música de trabalho, segundo Fisher, condenava, tanto os feitores quanto a condição de vida dos escravos, no período antes da Guerra Civil, além de fazer com que o trabalho passasse mais rápido.

Lazarus E. N. Ekwueme, em artigo de 1974, deixa clara, a sua posição, já no título do trabalho "Retenções musicais africanas no Novo Mundo". O autor buscou, então, semelhanças entre as músicas na África e nas Américas e afirmou, por exemplo, que uma dona de casa negra, na Louisiana, canta para seu bebê, não muito diferentemente do jeito de uma mãe jamaicana ou ainda de uma mulher Ewe, no Gana (EKWUEME, 1974, p.128). Apesar da aculturação das pessoas negras, no Novo Mundo, eles continuaram a tradição de empregar música na sua vida social e comunal, assim como persistiram, com certos elementos da melodia africana. Segundo o autor, a música ocupava um papel central, nos trabalhos realizados em grupo, não só porque funcionava como uma distração para o fardo do serviço, mas também porque servia para coordenar a energia do time de trabalho, cuja ação estava atrelada ao ritmo da música.

Lawrence Levine analisou as músicas de trabalho, cantadas pelos negros norteamericanos, no período pós-abolição, músicas essas que se tornaram mais seculares do que religiosas. Segundo Levine, após a escravidão, os negros estavam mais sujeitos do que antes às influências musicais de todos os tipos. No final do século XIX e começo do século $\mathrm{XX}$, brancos e negros do Sul dos Estados Unidos partilhavam um repertório de músicas populares. Apesar desse contato, a música afro-americana permanecia distinta. Em parte, porque as músicas brancas, que ouviam, já tinham sido influenciadas pelos estilos musicais negros. Outro fator da distinção é também a capacidade dos negros de colocar, em sua própria estética e necessidades sociais, as músicas que pegam emprestado. O ecletismo da música negra, secular, segundo Levine, foi composto, não somente da mistura de elementos brancos e negros, mas também da combinação de vários e diversos estilos comuns à cultura afro-americana (LEVINE, 1978, PP.195-197). O autor mostra, assim, uma visão da música 
negra, mais matizada que os autores citados acima, ao propor que ela não foi formada, unicamente, a partir de elementos africanos.

Levine propôs que a música, desde o tempo da escravidão até o século $\mathrm{XX}$, era tão valiosa na vida dos trabalhadores, que o papel do cantor líder assumia grande importância no progresso da atividade executada. Cantando, eles aliviavam as tensões, faziam o tempo passar mais rápido; e, se não mudavam as condições externas sob as quais trabalhavam, pelo menos sentiam motivação para sobreviver, tanto psicológica, quanto fisicamente, a essas condições.

Tanto na forma quanto na função, a música de trabalho era um instrumento comunitário. Ela permitia aos trabalhadores harmonizar seus movimentos físicos e suas necessidades psíquicas às dos outros trabalhadores, e possibilitava ainda, importantes meios de comunicação e expressão. A música afetou, substancialmente, o significado da própria experiência do trabalho. Citando Bruce Jackson, Levine expôs que, ao incorporar o trabalho à música, os trabalhadores negros resignificaram, como sua, uma atividade que eram forçados a executar.

Em relação ao Brasil, além dos viajantes que dedicaram algumas linhas sobre o assunto, folcloristas reuniram músicas utilizadas nos trabalhos dos carregadores.Augusto Pereira da Costa, em obra publicada em 1907, cita algumas cantilenas de carregadores de pianos de Recife, como:

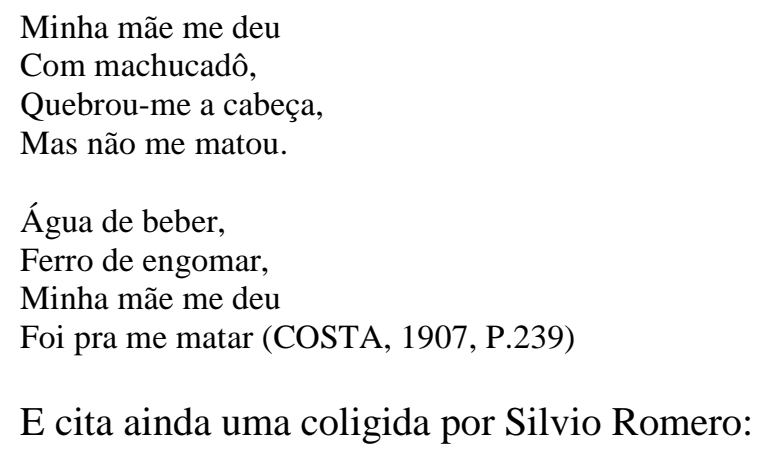

Bota a mão No argolão; Sinhazinha

Vai tocar;

Afinador

Vem afinar,

Sinhazinha

Vai pagar (COSTA, 1907, p.240). 
Manuel Querino, em A raça africana e os seus costumes na Bahia, afirmou que os trabalhadores ao ganho, de Salvador, cuja função de carregar era uma das principais, estavam organizados em diversos pontos da cidade. Esses pontos eram chamados de cantos, e eram dirigidos por um chefe a que apelidavam de capitão. Ao relatar a cerimônia de aclamação de um novo capitão, de um canto do bairro comercial, Quirino expõe que todo o canto desfilava em direção ao bairro das Pedreiras, e que eles entoavam, em dialeto ou patuá africano, uma monótona cantilena (QUERINO,1955).

Guilherme Santos Neves inicia seu artigo "Velhos e perdidos cantos de trabalho", publicado em 1966, com a afirmação um tanto saudosista de que "as cidades de hoje não mais apresentam o curioso espetáculo de outrora, quando, às vezes, percorriam as ruas os negros, carregadores de pianos" (NEVES, 1966, p.6). Este autor cita os relatos de viajantes em relação ao Rio de Janeiro, mas também faz menção à obra de Gilberto Freire, Casa Grande \& Senzala. Freire, referindo-se aos cantos de trabalho dos negros, pois estes "trabalharam sempre cantando" e "enchendo de alegria africana a vida brasileira", afirmou que "os pianos não se carregavam outrora sem que os negros cantassem:

É o piano de yoyô,

é o piano de yayá... (NEVES, 1966, p.6)

Os textos acima fazem mais um possível inventário das canções entoadas pelos carregadores em algumas partes do Brasil do que propriamente uma tentativa de análise das funções dessas músicas nas experiências desses trabalhadores. Quem caminhou nessa direção foi o historiador João José Reis, em artigo de 1993. Reis, baseado em viajantes e memorialistas, afirmou que os carregadores de Salvador, no século XIX, entoavam canções cantadas na língua da África. A música que "animava aqueles corpos podia ajudar a aliviar o peso sobre os ombros, mas, sobretudo, aliviava o espírito, permitindo aos africanos persistir, afirmar sua humanidade, não desesperar" (REIS, 1993, p.12). A música contribuía, assim, para assegurar alguma "estrutura de integridade comunitária" e também seria um instrumento de denúncia da escravidão. Reis considera que não seria surpresa que "além de canções africanas de trabalho, os ganhadores inventassem letras de crítica da escravidão e escárnio dos brancos" (REIS, 1993, p.12).

A música, segundo Reis, estava associada, diretamente, ao processo de trabalho. As cantilenas que davam o ritmo ao trabalho eram puxadas pelos capitães de canto. Os cantos, 
citados anteriormente por Quirino, foram descritos por Reis como grupos, etnicamente delimitados, que se reuniam para oferecer seus serviços em determinados locais da geografia urbana. Este autor afirmou que falta informações sobre como os capitães eram escolhidos, mas propôs como o modelo original dessa liderança poderia estar ligado a diversas tradições africanas. Além de conduzirem as músicas, os capitães de canto tinham ainda as seguintes funções: "contratar serviços com clientes, designar tarefas, receber e dividir a féria, mediar conflitos, porventura surgidos entre os ganhadores" (REIS, 1993, p.14).

As funções descritas acima, para os capitães de canto de Salvador, inclusive a de puxar a música, não eram muito diferentes das descritas para os capatazes entre os carregadores do Rio de Janeiro no século XIX. ${ }^{3}$ A figura desse líder, na organização do trabalho, se assemelha ainda com a relatada por Pereira da Costa para os condutores de mercadorias em Recife. Segundo ele, os carregadores "formavam-se em grupos a que chamavam de companhias, dirigidas por um mestre ou capataz; que distribuía o serviço e pagava o salário aos sábados" (COSTA, 1907, p.237).

Podemos perceber, portanto, que havia pontos comuns na organização do trabalho dos carregadores negros, em algumas partes do Brasil, como a figura do chefe do grupo e também a presença predominante da música, associada à execução da atividade. Mas, afinal, o que havia de específico, e também de comum, entre os cantos entoados pelos carregadores negros do Rio de Janeiro e a música de trabalho dos africanos no Mundo Atlântico?

Como vimos acima, a música estava fortemente associada ao trabalho de quase todos os tipos de carregadores do Rio, na primeira metade do século XIX. A avaliação dos viajantes sobre essas músicas, no entanto, era um tanto diversa. Alguns viam-nas como uma demonstração de tristeza e melancolia, por parte dos escravos; outros, como sinal da alegria; outros, ainda, as consideravam como perturbadoras de estrangeiros pacatos. Um consenso entre eles, no entanto, é que o capataz puxava o canto e utilizava uma matraca, que servia, não só para marcar o compasso, como para abrir caminho. Segundo Luccock,

\footnotetext{
${ }^{3}$ Entre as fontes que analisei para o Rio de Janeiro, não encontrei o termo "capitão", mas sim “capataz", que se referia ao chefe escolhido entre os próprios carregadores, e também o termo "feitor", que designava o fiscal encarregado pelo comerciante que contratasse o serviço dos carregadores para acompanhar o transporte das mercadorias, a fim de vigiar e controlar o trabalho.
} 
A fim de imprimir ritmo aos seus esforços e, principalmente uniformidade no passo, esse [o capataz] entoa sempre alguma cantiga africana, curta e simples, ao cabo do qual o grupo todo responde em alto coro (LUCCOCK, 1942, p.74).

$\mathrm{Na}$ passagem acima, podemos perceber vários elementos comuns, aos cantos de trabalho de outros espaços do Mundo Atlântico. O primeiro deles é a figura do puxador de canto. Levine expôs, que os cantores líderes tinham papel fundamental no ritmo do trabalho, no fornecimento de instruções e na produção de divertimentos. A importância desses líderes para o desenvolvimento das atividades era percebida até pelos contratadores e o autor cita um caso relatado pelo Baltimore Sun, em 1903, em que um chefe branco, de uma ferrovia, em Maryland, cometeu o erro de dispensar um trabalhador, que parecia estar cantando, mais do que trabalhando. Os outros empregados negros tornaram-se displicentes e passaram a reclamar a volta do cantor. E quando tiveram o pedido atendido, passaram a trabalhar com energia renovada (LEVINE, 1978, p.210). Miles Mark Fisher afirmou que, nos tempos da escravidão, cantores eram pagos para fazer o trabalho aumentar nas plantações do Sul ao induzir os escravos a cantar. Esses "cantores chefes" tinham várias designações e, geralmente, eram mulheres (FISHER, 1990, p.21).

O segundo elemento é a forte relação entre o canto e o ritmo do trabalho. Luccock expôs que a música era fundamental, não só para imprimir ritmo, como também para dar uniformidade aos passos dos ganhadores. Segundo Henry Chamberlain, que esteve no Rio de Janeiro em 1819, "a fim de manter a regularidade do passo, tão necessária para produzir uniformidade de esforço, o capataz canta umas palavras africanas às quais todos respondem em coro. E assim, cantando e marchando juntos, executam o trabalho contratado" (CHAMBERLAIN, 1943, p.165). Ekwueme, analisando tanto as músicas de trabalho das Américas quanto as da África, afirmou que elas eram essenciais, num trabalho realizado em grupo, e tinham justamente a função de coordenar a energia do time de trabalhadores cuja a ação estava diretamente ligada com o ritmo da música (EKWUEME, 1974, p.129).

O terceiro elemento comum, entre as músicas entoadas pelos transportadores do Rio, e as dos trabalhadores negros, no Mundo Atlântico, é a questão da forma. Luccock afirmou que o capataz entoava uma cantiga africana, curta e simples, que era respondida pelo grupo. Chamberlain fez observação semelhante na passagem acima, ao informar também que o capataz entoava algumas palavras que eram respondidas em coro. A forma "chamada e resposta" é descrita por Ekwueme, como sendo africana, e, tendo sido 
transplantada para as Américas, consistia, justamente, em que um solista, ou um pequeno grupo, tomasse a liderança e o resto do grupo, ou o coro, respondesse cantando ou tocando a mesma melodia ou uma melodia diferente, numa velocidade correspondente (EKWUEME, 1974, p.136). Levine, por sua vez, expôs que, as músicas de trabalho dos negros americanos, poderiam ser cantadas, tanto na forma chamada e resposta, em que os trabalhadores respondiam, ao líder, com palavras suas, como também por canções em que havia só chamadas e não respostas (LEVINE, 1978, p.209).

Outro ponto comum é que, a música era importante, não só para imprimir o passo da atividade, mas também para fazer com que o tempo passasse mais rápido e aliviasse a alma dos trabalhadores negros. Luccock afirmou que:

Prosseguem nesse canto enquanto dura o trabalho, parecendo que com isso aliviam a carga e alegram seus ânimos. Tinha por vezes a impressão de que essa gente não era insensível ao prazer das recordações, assim avivadas, de um lar que haviam perdido e que jamais tornariam a ver (LUCCOCK, 1942, p.74).

Essa passagem aponta para os significados dessas músicas que, provavelmente, extrapolavam a função de organizar o trabalho. Luccock levantou a possibilidade de elas serem uma forma de reavivar as lembranças da sua terra natal e, com isso, aliviar a carga e alegrar os ânimos. Levine expôs, em relação aos trabalhadores negros dos Estados Unidos, justamente que a música aliviava as tensões e fazia o tempo passar mais rápido. Reis, por sua vez, observou que a música servia, para os ganhadores de Salvador, como um alento para a alma, uma forma de afirmar a sua humanidade e não desesperar (REIS, 1993p.12).

Jean Baptiste Debret, presente no país entre 1816 e 1831, afirmou que, entre os carregadores de café, havia "um capataz entusiasta, capaz de animar os homens com suas canções improvisadas" (DEBRET, 1978, p.237, vol.1). A improvisação é vista por Levine como um traço marcante das músicas de trabalho norte-americanas. Utilizando uma estrutura familiar e, provavelmente, melodias também conhecidas, os trabalhadores negros permitiam a si próprios um amplo escopo para improvisarem novas palavras que tinham a ver com o seu redor (LEVINE, 1978, p.206).

A característica da improvisação permitiu, portanto, que os negros cantassem elementos próprios de seu cotidiano. Dessa forma, nas letras das músicas, poderíamos encontrar o que havia de específico nas canções dos carregadores negros. A única letra a 
que tive acesso, referente ao Rio de Janeiro, no entanto, foi a registrada pelo memorialista Luís Edmundo e diz respeito a uma marcha entoada por alguns carregadores de cangalhas:

Maria, rabula, auê

Calunga, auê (EDMUNDO,2000, p.45).

Embora não tenha conseguido apreender o sentido desta letra, me chamou atenção a palavra "calunga". Slenes afirmou que a predominância de escravos, vindos da África Central, favoreceu a formação de uma identidade étnica bantu no Brasil do século XIX. A palavra kalunga fazia parte, justamente, do complexo lingüístico bantu e significava a linha divisória, ou "a 'superfície', que separava o mundo dos vivos daqueles dos mortos" (SLENES, 1991-1992, P.53). Não vem ao caso, neste momento, discutir quais eram as diferentes acepções que a palavra poderia ter para os diversos povos bantu, ou até mesmo qual poderia ser o sentido dela na música acima. O que importa é que ela demonstra a presença de uma palavra africana, e, mais ainda, bantu, numa possível música entoada pelos carregadores, no Rio de Janeiro.

Tentar traçar um panorama indicador desses trabalhadores que entoavam as cantigas, pelas ruas da cidade do Rio de Janeiro, no século XIX, é uma tarefa um tanto árdua. Mary Karasch afirma que é difícil estabelecer as identidades específicas da maioria africana da população devido à extraordinária diversidade étnica do Rio. Enquanto Salvador tendia a receber uma mostra mais restrita da África Ocidental, o Rio importava escravos da África Ocidental e Oriental (KARASCH, 2000, p.42).

Karasch nota que, antes de 1811, 96,2\% dos escravos do Rio vieram do CentroOeste Africano. Embora o número tenha diminuído, após isso, nunca caiu para menos de 66\%. Em nenhum período, os escravos provenientes da África Ocidental chegaram perto de um quarto do tráfico para o Rio, pois, menos de $2 \%$, eram importados, diretamente, dessa região. A porcentagem mais alta $(6 \%$ a $7 \%)$ de africanos ocidentais, na cidade, reflete o tráfico entre a Bahia e o Rio, principalmente depois de 1835. A importância crescente, da África Oriental, na cidade, reflete-se na porcentagem do número de escravos, vindos dessa região, entre 16,8\% e 26,4\% dependendo do período (KARASCH, 2000, p.50).

Uma forma de tentar identificar quem eram os carregadores da cidade do Rio de Janeiro, no século XIX, é acompanhar as licenças obrigatórias para que os trabalhadores, 
sejam eles escravos ou forros, saíssem ao ganho, pelas ruas da cidade. Para a primeira metade do século XIX, temos um total de 169 licenças, referentes a 199 negros. Desses, cinco são libertos que requerem licenças para si mesmos (2,51\%), e os outros 194 são escravos $(97,49 \%) .{ }^{4}$ Os dados demográficos da cidade nos informam sobre a proporção de libertos e escravos. Em 1799, do total de 43.376 habitantes do Rio, 34,6\% eram escravos, enquanto os libertos 20,3\%. Em 1849, a porcentagem de escravos era um pouco maior $38,9 \%$, mas é preciso considerar que a população do Rio havia crescido, enormemente, e contava 205.906 pessoas na cidade. Os libertos, nessa data, somavam 5,21\% do total da população. Considerando, agora, só a população negra, a partir do Censo de 1849, temos que $88,02 \%$ deles eram escravos e $11,98 \%$, libertos. Analisando, somente os dados das licenças referentes à década de 1840, que estariam mais perto do Censo, temos, então, 3,1\% de libertos e $96.9 \%$ de escravos (KARASCH, 2000, pp. 109 e 112). A proporção de libertos e cativos, entre os trabalhadores ao ganho, parece não ser tão diferente da encontrada na população negra total da cidade.

Através das licenças, podemos perceber, também, que, do total de 199 negros presentes nelas, 2,51\% eram crioulos, isto é, nascidos no Brasil; 70,85\% eram africanos, e, $26,64 \%$, não tiveram a nacionalidade declarada. Segundo o Censo de 1849 , dentro do total da população negra contabilizando os escravos e forros conjuntamente, 33,1\% eram brasileiros e 66,9\% eram estrangeiros (KARASCH, 2000, p.112). Comparando os diferentes dados, poderíamos dizer que o mercado dos escravos ao ganho, na primeira metade do século, era majoritariamente africano, tendo apenas uma ínfima parcela de brasileiros Os africanos continuaram a ser maioria, no trabalho ao ganho, na segunda metade do século, em que constituíam $76,53 \%$, contra $15,97 \%$ brasileiros e $5.5 \%$ não tiveram suas origens especificadas.

Os dados da licença apontam o Centro-Oeste Africano (60.3\%) e para a África Oriental $(20.6 \%)$ como a terra natal, provável, da maioria dos ganhadores africanos do Rio. Os da África Ocidental computavam apenas 10.9\%. Esses percentuais, das principais regiões exportadoras da África, se assemelham, portanto, aos encontrados para a cidade, no mesmo período. O Centro-Oeste Africano continuou a ser a área de procedência da maioria

\footnotetext{
${ }^{4}$ AGCRJ- Códices: 6.1.44 a 6.1.47
} 
(44,4\% ) dos ganhadores da cidade, na segunda metade do século XIX, seguidos pelos da África Ocidental $(23,5 \%)$, da África Oriental (13\%), e pelos africanos de nações desconhecidas $(19,1 \%)$ (SOARES, 1998, pp. 115-116).

O fato de termos encontrado uma palavra bantu na única letra de uma música entoada pelos carregadores do Rio de Janeiro, no século XIX, vai de encontro aos dados da licença, que apontam, justamente para uma maioria proveniente do Centro-Oeste Africano, entre os ganhadores. Esse elemento significou, portanto, uma das especificidades dos carregadores do Rio, em relação aos trabalhadores negros de outras regiões do Mundo Atlântico. Enquanto a maioria dos escravos trazidos para o Centro-Sul do Brasil, durante a primeira metade do século XIX, era do Centro-Oeste Africano, em Salvador, nesse mesmo período, por exemplo, a maioria era de nagô. Por isso, embora os carregadores das duas cidades, cantassem, enquanto trabalhavam, o canto entoado, com certeza, não era o mesmo.

Se pensarmos que a música foi um dos elementos utilizados pelos africanos para reconstruírem suas identidades, no Novo Mundo, veremos que os grupos de procedência, aos quais pertenciam, tiveram, com certeza, um papel fundamental, mas não único. Seguindo as proposições de Fredrik Barth, as identidades étnicas devem ser analisadas pelo aspecto relacional, isto é, precisamos verificar, dentro de um contexto histórico específico, como os grupos se autodefiniam e eram definidos por outros, e como as fronteiras, estabelecidas entre eles, implicavam em conflitos. As configurações étnicas estiveram, portanto, em permanente processo de transformação, e diferiam, de acordo com o tempo, lugar e situação. Sendo assim, se o passado africano foi um elemento presente, nas músicas cantadas pelos trabalhadores negros, ele passou a ser reinscrito, de acordo com os contextos históricos específicos, que poderiam ser diferentes, num mesmo lugar, ao longo do tempo, mudando, assim, a própria natureza do que era cantado.

Pudemos perceber semelhanças, no Mundo Atlântico, no fato de que os negros entoavam músicas, durante o processo de trabalho. Essas músicas faziam parte do processo em si, seja dando-lhe ritmo ou fazendo com que passasse mais rápido. As semelhanças, também, estavam presentes, na forma como eles cantavam essas canções, a "chamada e resposta", além de emprego constante da improvisação.

Vimos que alguns autores interpretaram essas semelhanças como tendo, unicamente, uma matriz africana, e sendo essa matriz a raiz das identidades criadas pelos africanos, nas 
Américas, e pelas quais eles estariam atrelados, por uma cadeia inquebrável. Creio que a constatação dessas similitudes deve ser o ponto de partida e não o de chegada. O que essas músicas poderiam significar, de acordo com o contexto específico dos grupos que a entoavam? Como os trabalhadores utilizaram esses elementos comuns para cantar elementos próprios de sua realidade? Acredito que a tradição cultural que os africanos trouxeram não deve ser vista de forma essencializada e concordo com Stuart Hall que diz a questão não é o que a tradição faz da gente, mas o que a gente faz da tradição (HALL, 2003, p. 44). O próximo passo dos estudos dedicados a música de trabalho dos negros deve ser, portanto, averiguar não só o que há de comum entre as canções do Mundo Atlântico, mas também o que há de diferente, de específico, além de buscar quais outras influências receberam, além da africana.

\section{REFERÊNCIAS BIBLIOGRÁFICAS:}

ALGRANTI, Leila Mezan. O feitor ausente - estudo sobre a escravidão urbana no Rio de Janeiro. Petrópolis: Vozes, 1988.

ASSUNÇÃO, Mathias Röhrig. "From slave to popular culture: the formation of afro-brazilian art forms in nineteenth-century Bahia and Rio de Janeiro". Ibero Americana, III, 12 (2003). BARTH. Fredrik. "Grupos étnicos e suas fronteiras" in: Philippe Poutignat e Jocelyne Sreiff-Fenart. Teorias da etnicidade. São Paulo: Fundação Editora da UNESP, 1998.

BIARD, F. Deux annés au Brésil. Paris, 1862.

CHAMBERLAIN, Henry. Vistas e costumes da cidade e arredores do Rio de Janeiro em 1819-1820, segundo desenhos feitos pelo Tenente Chamberlain R. A._São Paulo: Kosmos, 1943.

COSTA, Augusto Pereira da. "Folk-Lore Pernambucano"; Revista do IHGB, 1907; Tomo L; Parte I

COSTA E SILVA, Alberto da. "Africa-Brazil-Africa during the Era of the Slave Trade". In: Jose C. Curto; Paul E. Lovejoy. Enslavng connections: changing cultures of Africa and Brazil during he era of slavery. New York: Humanity Books, 2004. 
CRUZ, Maria Cecília Velasco e. "Tradições negras na formação de um sindicato: sociedade de Resistência dos trabalhadores em trapiche e café, Rio de Janeiro, 1905-1930." Afro-Ásia 24 (2000). CEAO/ FFCH/ UFBa.

DEBRET, Jean-Baptiste. Viagem pitoresca e histórica ao Brasil. Belo Horizonte: Itatiaia; São Paulo: USP, 1978, vol.1

EDMUNDO, Luís. O Rio de janeiro no tempo dos vice-reis (1763-1808). Brasília: Senado Federal, 2000.

EKWUEME, Lazarus E. N. "African-Music retentions in the New World". The black perspective in Music, vol.2,n.2 1974.

EWBANK, Thomas. Vida no Brasil ou Diário de uma visita à Terra do Cacaueiro e da Palmeira. São Paulo: Ed. da USP; Belo Horizonte: Ed. Itatiaia, 1976.

FISHER, Miles Mark. Negro slave songs in the United States. New York: Carol Publishing Group, 1990.

GILROY, Paul. O Atlântico negro: modernidade e dupla consciência. Rio de Janeiro: Centro de Estudos Afro-Asiáticos, 2001.

HALL, Stuart. Da Diáspora: Identidades e mediações culturais. Belo Horizonte: UFMG: Representações da UNESCO no Brasil, 2003.

KARASCH, Mary C. A vida dos escravos no Rio de Janeiro (1808-1850) São Paulo: Companhia das Letras, 2000.

KIDDER, Daniel Parish. Reminiscências de viagens e permanência no Brasil. São Paulo: Livraria Martins, 1940.

LARA, Silvia Hunold. "Blowing in the Wind: E. P. Thompson e a experiência negra no Brasil" in: Projeto História. São Paulo (12), out. 1995.

LEVINE, Lawrence W. Black culture and black consciousness. New York: Oxford University Press, 1978.

LOCKE, Alain. The Negro and his music. New Hampshire: Ayer Company, 1988.

LUCCOCK, John. Notas sobre o Rio de Janeiro e partes meridionais do Brasil. Tomadas durante uma estada de dez anos, de 1808 a 1818. São Paulo: Livraria Martins, 1942.

MORGAN, Philip D. "The cultural implications of the Atlantic Slave Trade: African Regional Origins, Americans Destinations and New World Developments". Slavery and Abolition, vol.18, n. 1, 1997. 
NEVES, Guilherme Santos. "Velhos e perdidos cantos de trabalho". A Gazeta. Vitória, 01 de maio de 1966, suplemento literário.

REIS, João José. “A greve negra de 1857 na Bahia”. Revista USP, 18 (1993).

SILVA, Marilene Rosa Nogueira da. Negro na rua: a nova face da escravidão. São Paulo: Hucitec; Brasília: CNPq, 1998.

SLENES, Robert W. Robert W. Slenes, “'Malungu, nagoma vem!': África coberta e descoberta no Brasil", Revista USP, nº 12, dez/fev 1991-1992.

SOARES, Luiz Carlos. "Os escravos de ganho no Rio de Janeiro do século XIX". Revista Brasileira de História, 16 (Mar/ ago.1998). Marco Zero/ ANPUH.

STUCKEY, Sterling. Slave culture: Nationalist theory and the foundations of black America. New York, Oxford: Oxford University Press, 1987.

\section{FONTES:}

Arquivo Geral da Cidade

Licenças para escravos ao ganho- Códices 6.1.44 a 6.1.47 